\title{
PORTAIS EDUCACIONAIS E SUAS CARACTERÍSTICAS: CONTRIBUIÇÕES PARA O ESTADO DA ARTE
}

\author{
J. B. BOTTENTUIT JUNIOR \\ Universidade Federal do Maranhão - UFMA, Campus Universitário do Bacanga \\ Departamento de Educação II, São Luís - MA \\ jbbj@ufma.br
}

Artigo submetido em junho/2012 e aceito em julho/2013

\section{RESUMO}

Neste artigo pretende-se discutir acerca da Internet, sua evolução, bem como explorar uma das categorias de sites que mais tem crescido nos últimos tempos: os portais. Atualmente, é possível observar a sua existência em todos os campos de atuação, tais como os empresariais, jornalísticos, políticos e também educacionais. Assim, discute-se de forma mais detalhada as características dos portais educacionais e suas aplicabilidades, além disso, apresenta-se alguns exemplos de estudos realizados tanto no Brasil como em Portugal no âmbito dos portais educacionais.

PALAVRAS-CHAVE: Internet, Sites, Portais, Portais Educacionais

\section{EDUCATIONAL PORTALS AND FEATURES: CONTRIBUTIONS TO THE STATE OF THE ART}

\section{ABSTRACT}

This article intends to discuss about the Internet, its evolution and to explore one of the categories of sites that has grown more in recent times: the portals. Currently, it is possible to observe its existence in all fields, such as business, journalism, political and also

educational. Thus, it is discussed in more detail the characteristics of educational portals and their applicability, also presents some examples of studies in Brazil and in Portugal as part of educational portals. 


\section{PORTAIS EDUCACIONAIS E SUAS CARACTERÍSTICAS: CONTRIBUIÇÕES PARA O ESTADO DA ARTE}

\section{INTRODUÇÃO}

Antes de falar especificamente sobre os portais, é necessário tecer alguns comentários sobre a Internet, pois se os portais são hoje poderosos veículos de difusão da informação, é porque a Internet evoluiu e permitiu o aparecimento de múltiplos formatos de acesso a vídeos, imagens, texto, animação e interatividade.

A Internet permite o acesso remoto, bem como a troca de dados (digitais e analógicos) a longas distâncias com rapidez e precisão. Simões $(2005$, p.11) afirma que "através da Internet, acede-se a uma biblioteca interativa, multifacetada e sempre disponível".

Esta rede global de computadores é a maior rede informática existente no mundo e permite o acesso a um repositório de dados imenso, podendo ser acessada por qualquer pessoa desde que disponha de equipamento necessário. Segundo Castells (2004, p.15), "as redes são formas muito antigas da atividade humana, mas actualmente essas redes ganharam uma nova vida ao converterem-se em redes de informação, impulsionadas pela Internet".

Os meios de acesso podem ser realizados de múltiplas formas (via cabo, discado, via modem portátil ou mesmo sem fio através da tecnologia wireless). Porém, para chegarmos a este atual nível de desenvolvimento tecnológico, diversos investimentos foram realizados, bem como a participação de uma série de pessoas que deram contribuições significativas ao longo destes anos. A Internet não possui um dono, porém "as redes que compõe a Internet são operadas por múltiplas e diferentes organizações, desde universidades, organismos governamentais, instituições de pesquisa, instituições militares, empresas, etc." (SILVA \& REMOALDO, 1995, p.13). Neste sentido, as empresas e as pessoas que estabelecem ligação à rede (usuários) é que acabam por, indiretamente, serem responsáveis por ela, ou seja, a Internet é paga pelas pessoas que à utilizam.

No decurso desta secção, tentou-se conceituar a Internet com objetivo de oferecer um entendimento acerca desta tecnologia, mas, visando um maior aprofundamento desta temática, torna-se necessário nos reportarmo-nos ao percurso histórico, tentando entender sua origem e evolução até os dias atuais.

\section{A EVOLUÇÃO DA INTERNET}

Os períodos de guerra tiveram grande importância para o desenvolvimento das tecnologias. A este respeito Edwards (1996) refere que a II Guerra Mundial foi marcada pelo aparecimento dos computadores para a execução de cálculos matemáticos, decifração de códigos e resoluções de problemas de balística. Já a Guerra Fria foi marcada pelo desenvolvimento de tecnologias que permitiram a comunicação em rede, com auxílio dos computadores. Sabe-se que a Internet surgiu durante a Guerra Fria, na década de 60, mais precisamente em Setembro de 1969 pela mão da Advanced Research Projects Agency (ARPA), do Departament Office Defence - DOD - (Departamento de Defesa dos Estados Unidos).

Segundo Silva \& Remoaldo (2003) e Castells (2002, 2004), os Estados Unidos, temendo um possível ataque por parte da ex União Soviética (URSS), desenvolveu uma rede capaz de trocar 
dados entre as suas bases militares. O objetivo era a comunicação segura dos comandos e estratégias de guerra, bem como a recuperação de dados com maior rapidez, caso houvesse algum ataque às bases militares. Esta primeira rede recebeu o nome de ARPANET $^{1}$, que podemos classificar como o maior fenômeno midiático de todos os tempos, (ALVES, 2000).

Segundo Martins (2005), a Internet atingiu 50 milhões de usuários em apenas 5 anos, enquanto para outras tecnologias, como o rádio, foram necessários 38 anos, a TV 16 anos e a TV a Cabo 10 anos. Isto demonstra a rápida popularidade desta ferramenta que modificou definitivamente os meios de transmissão da informação e comunicação. "Cada vez mais popular, a nova mídia emula a linearidade da TV, dos impressos e do rádio, ao mesmo tempo em que integra características interativas completamente inovadoras" (PÓVOA, 2000, p.57).

Com o fim da Guerra Fria, os militares permitiram que as universidades também pudessem ter acesso a essa poderosa forma de comunicação. Neste sentido, houve um rápido interesse por parte da maioria das universidades e centros de pesquisa, pois poderiam comunicar com outros investigadores das mais diversas universidades no mundo, potencializando futuras investigações e o intercâmbio de ideias. Isto obrigou a uma separação da rede em duas partes: a primeira era chamada de MILNET para comunicações militares e a segunda ARPANET, para a comunicação entre as universidades e centros de pesquisa (AGNER, 2002).

Até então, a rede só permitia a transmissão de informações textuais, porém, em 1990, foi desenvolvida por Tim Berners-Lee no CERN (Conseil Européen pour la Recherche Nucléaire ${ }^{2}$ ) a World Wide Web (WWW), o primeiro navegador Web que permitia a abrangência mundial da rede. A sua interface era muito simples e a grande maioria das informações eram disponibilizadas em formato de texto e com poucas imagens. Segundo Castells (2004, p.32), a partir de então:

Uma série de hackers em todo o mundo começou a desenvolver os seus próprios browsers, baseando-se no trabalho de Berners-Lee. A primeira versão foi a Erwise, desenvolvida no Instituto Tecnológico de Helsínquia, em Abril de 1992. Pouco depois, Viola, na Universidade de Berkeley, criou a sua própria adaptação.

Godfrey (2006), no seu artigo sobre a arquitetura e evolução dos browsers modernos, apresenta os diversos navegadores que surgiram posteriormente ao WWW, bem como a evolução verificada nas suas diferentes versões. (ver figura 1)

Em 1992 surge o Lynx, em 1994 o Mosaic, em 1995 o Netscape Navigator, em 1996 o Internet Explorer, em 1997 o Opera, em 1998 o Mozila, em 1999 o Konqueror, em 2002 o Galeon, em 2003 o FireFox e o Epiphany. Alguns destes navegadores não atingiram grande popularidade, já outros (como o FireFox e o Internet Explorer) evoluíram bastante e continuam no topo das preferências dos usuários. Mais recentemente outros navegadores vêm ganhando popularidade, como por exemplo, o Opera e o Google Chrome.

O mesmo autor chama ainda a atenção para o surgimento da W3C (World Wide Web Consortium) em 1994, que consiste num consórcio de empresas de tecnologia, fundada por Tim Berners-Lee, que tem como objetivo o desenvolvimento de protocolos de comunicação comuns,

\footnotetext{
${ }^{1}$ Como o ataque militar nunca ocorreu de facto, deu-se nesta época um pontapé inicial para as comunicações via computadores a longas distâncias.

${ }^{2}$ Conselho Europeu para Pesquisa Nuclear - http://www.cern.ch 
assegurando a sua interoperabilidade ${ }^{3}$, ou seja, desenvolve padrões para a criação e a interpretação dos conteúdos para a Web. Isto permite que os sites desenvolvidos, segundo esses padrões, pudessem ser acessados e visualizados por qualquer pessoa, independentemente de hardware (computador) ou software (navegador) utilizados, ou seja, independentemente do navegador (browser), o usuário pode visualizar o mesmo conteúdo.

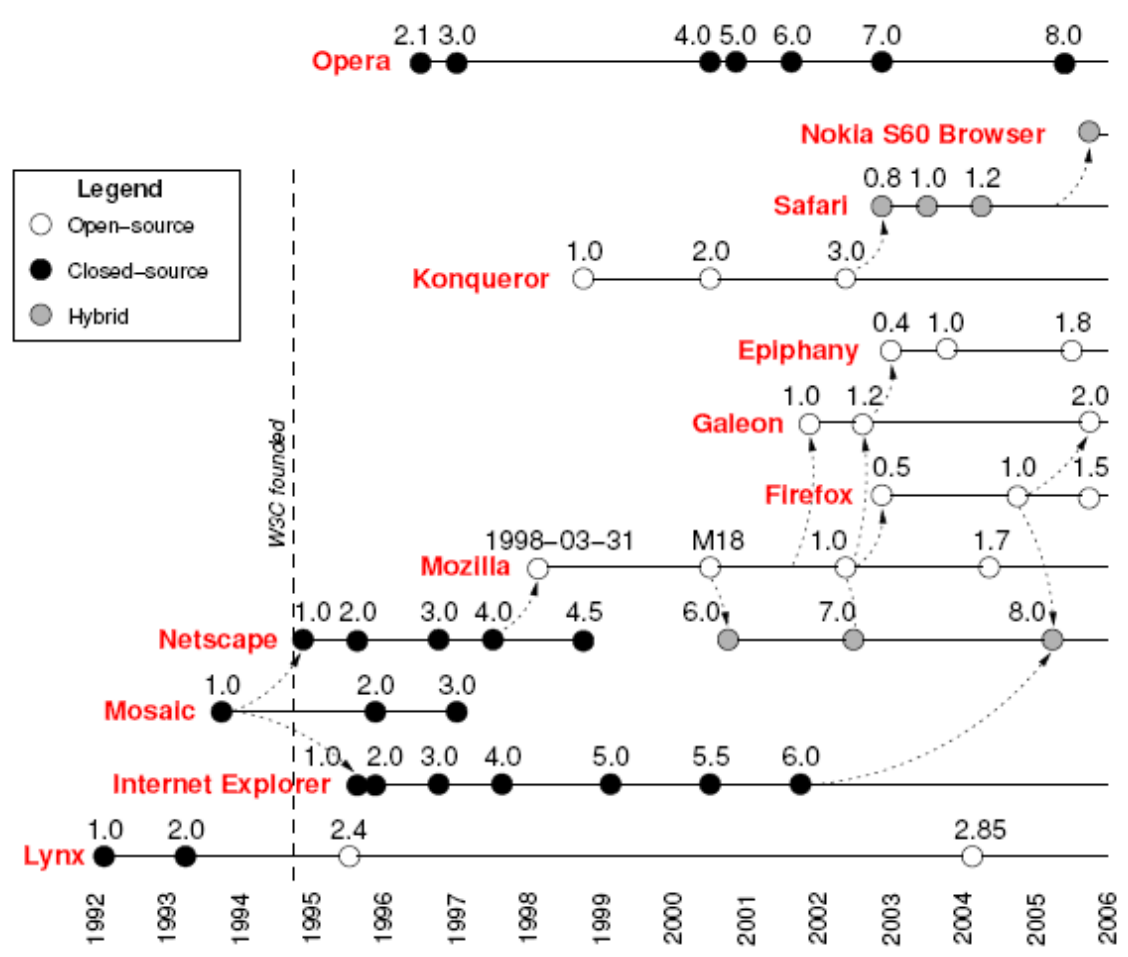

Figura 1: Evolução dos Navegadores Web segundo Godfrey (2006)

Após o surgimento dos navegadores, uma série de novas ferramentas foram criadas. A título de exemplo temos o correio eletrônico (e-mail), que permitiu a substituição, em grande parte, da correspondência postal. Hoje em dia, este meio possibilita a troca de mensagens com maior rapidez e economia, permitindo ainda que se anexem arquivos em todos os formatos de mídia (som, texto, imagem, animação, gráfico, etc.).

Em seguida, houve necessidade de comunicar-se em tempo real - comunicação síncrona (chat) - para que as pessoas pudessem transmitir informações indiferente do tempo e espaço. Hoje em dia, através deste meio, é possível transmitir todos os tipos de mídia (em tempo real), com a possibilidade de fazer conferências sobre temas gerais ou específicos, debates interinstituições, otimizando a sua utilização em diversas áreas do saber como a educação, a saúde, o governo, as indústrias, etc. Segundo Castells (2004, p.20), “a criação e desenvolvimento da Internet é uma extraordinária aventura humana. Mostra a capacidade das pessoas para

\footnotetext{
3 É a habilidade de dois ou mais serviços, desenvolvidos em diferentes organizações com diferentes plataformas, trocarem informações, ou seja, colaborarem de maneira transparente, independentemente de qual a linguagem de programação em que esse serviço tenha sido desenvolvido. Fonte: Piazza (2007).
} 
transcender as regras institucionais, superar as barreiras burocráticas e subverter valores estabelecidos no processo de criação de um novo mundo".

Nesse sentido, com o desenvolvimento da Internet e da fixação desta tecnologia como canal de comunicação, informação e conhecimento, diversos estudiosos (Tim Berners-Lee, Pierre Levy, Manuel Castells, Jackob Nielsen) debruçaram-se sobre esta poderosa ferramenta, a fim de perspectivarem as mudanças que esta tecnologia poderia acarretar ao mundo. A Internet veio revolucionar a forma como lidamos com a informação, mudando antigas práticas, tornando o mundo mais ágil e dinâmico, criando, inclusive, novas culturas. Segundo Castells (2004), a cultura da Internet caracteriza-se por ter uma estrutura em quatro estratos sobrepostos:

- A cultura tecnomeritocrática - que constitui uma rede de pessoas que trabalham em cooperação em torno de projetos tecnológicos;

- A cultura hacker - que procura desenvolver, explorar e aprender através da rede;

- A cultura comunitária virtual - que vê na Internet uma grande aldeia, em que é possível a troca de informações e conhecimentos;

- A cultura empreendedora - que consegue ver na rede oportunidades de negócios, bem como um meio de subsistência.

A Internet também propiciou um conjunto de novas profissões para suportar os sistemas online. Juntas, estas culturas, contribuem para uma ideologia de liberdade muito generalizada no mundo da Internet.

\section{CATEGORIAS DE SITES NA WEB}

O número de páginas - sites - na Internet vem aumentando de forma exponencial a cada ano, tornando a Web um espaço rico e muito diversificado que contém uma série de recursos como sejam: notícias, esporte, entretenimento, informação, conteúdos variados, animações e curiosidades, podendo integrar vários tipos de mídia (como exemplo: o vídeo e o rádio).

Considerando a diversidade de sites disponíveis na Internet, houve a necessidade de se criarem categorias, para que, desta forma, os usuário pudessem facilmente identificar o propósito de cada espaço na rede. Gonçalves (2002) considera os sites como verdadeiros sistemas de informação e desta forma categorizou-os da seguinte forma:

- Sites de notícias: nesta categoria, são incluídos os jornais, as revistas, os canais de rádio e TV disponíveis online;

- Sites de negócios: estão englobados os sites destinados a compra e venda de produtos e serviços (e-commerce e e-business), bem como os sistemas de apoio a clientes e marketing online;

- Sites temáticos: sites culturais, de esporte, ambientais, de ciências e tecnologia etc.

- Sites educativos: enquadram-se os sistemas de educação a distância, ambientes lúdico-didáticos, ambientes de ensino e aprendizagem, etc.

- Sites institucionais: fazem parte os sites ministeriais, governamentais, institucionais, das fundações, dos comités e dos partidos;

- Portais: educativos, corporativos, financeiros, infantis, escolares, jornalisticos.

- Motores de Busca: enquadram todos os sites, permitindo a realização de pesquisas na Web como, o Google, o Cadê, o Sapo, o Yahoo, etc.

- Sites pessoais: englobam todos os sites concebidos por alunos, professores e profissionais que desejam divulgar o seu currículo, os seus trabalhos e experiências através da Web. 
Carvalho, Simões \& Silva (2004, p.22) categorizam os sites relativamente à sua função, classificando-os como:

- Expositor de informação - o site é visto como um álbum, uma exposição ou um portfólio que possibilita uma "leitura", mais ou menos organizada, numa área de interesse;

- Coletor de informação - a informação é fornecida pelo usuário, por exemplo, através de um formulário;

- Meio de comunicação entre usuários interessados num dado assunto, através de uma ferramenta de comunicação (exemplo um fórum), podendo o site ser considerado como um "ponto de encontro" entre usuários;

- Instrumento de trabalho para os usuários desenvolverem uma atividade específica previamente planejada pelo seu autor (exemplo: WebQuest, exercícios com correção automática, simulações).

Estas categorias, de um modo geral, tentam classificar os sites quanto às suas características e utilidades. É possível ainda criar subcategorias para os sites de acordo com a sua área específica. No nível educacional, por exemplo, seria possível enumerar uma vasta gama de exemplares, tais como: sites de escolas, sites de associações de pais e professores, sites de softwares e recursos educativos, sites de projetos, redes telemáticas, blogs educativos, entre outros. Este conjunto de categorias cresce a cada ano, pois, com a evolução da Web, novos recursos são integrados, havendo a necessidade de novas classificações.

Para Carvalho (2006), os sites educativos encontram-se na sua quarta fase de desenvolvimento e devem ter em conta os seguintes critérios: simplicidade e sobriedade, interatividade, facilidade de uso e de pesquisa, a informação deve ser direcionada para diferentes setores do público, deve ter ferramentas de comunicação como o correio eletrônico, fórum, chat, vídeo/ audioconferência, deve permitir a edição colaborativa online, garantir a possibilidade de acesso a tecnologias móveis, visando uma aprendizagem ubíqua.

Kalinke (2003) e Simões (2005) utilizam níveis para explicar o processo de desenvolvimento da interatividade das páginas Web, atribuindo os seguintes níveis:

- Estático - Não possuiu hiperligações, tal qual um livro de papel. A informação não é alterada nem reage à atividade do usuário.

- Hipertexto - Possui hiperligações que não modificam a informação incluída na página. A navegação é determinada pelo usuário.

- Ativa (Animação) - Inclui mecanismos (ou hiperligações) para ativar uma imagem animada autônoma.

- Escreve e Envia - Inclui formulário para escrever texto, obtendo automaticamente uma resposta.

- Manipula e Verifica - Inclui imagens ou textos passíveis de serem manipulados, obtendo automaticamente uma resposta.

- Insere e verifica - Inclui mecanismos de entrada de textos ou imagens, obtendo automaticamente uma resposta.

A Internet coloca à disposição de todos, um conjunto de funcionalidades básicas que abrem infinitas possibilidades de desenvolvimento pessoal e gestão de atividades pessoais, laborais, lúdicas, etc. Entre as atividades mais comuns que as páginas Web podem realizar encontram-se: a facilidade de procurar informação, facilidade na distribuição de materiais educativos online, possibilidade de 
comunicação com outras pessoas, possibilidade de publicação de materiais, realização de aprendizagens, gestão administrativa e comercial, realização de publicidade, entretenimento e motivação online, etc.

No entanto, entre as categorizações dos sites, encontramos em Marques (1999) a preocupação em especificar algumas classificações das páginas Web de interesse educativo, tais como:

- As lojas virtuais - constituem-se em pontos de venda e distribuição de todo tipo de materiais didáticos e recursos complementares;

- Ambientes de tutoria e formação online - oferecem assessoria, aulas com auxílio de tutores, cursos, universidades virtuais com atividades de ensino e aprendizagem;

- Sites com publicações eletrônicas - são páginas na Web que oferecem uma grande quantidade de artigos, revistas, teses e dissertações para download e consultas;

- Sites de professores e investigadores - são páginas de professores universitários e investigadores que oferecem, para além dos dados dos autores, um conjunto de recursos que podem ser de interesses educativo;

- Sites temáticos de assuntos educativos - são páginas que oferecem aos usuários um conjunto de recursos e conteúdos acerca de um determinado tema educativo;

- Sites de redes de escolas - são sites de escolas que oferecem informações escolares bem como materiais e eventos realizados por estas instituições;

- Sites de bibliotecas - são espaços que facilitam a localização de livros, artigos e documentos e devem dispor de índices muito bem estruturados (por autores, áreas e assuntos), bem como um potente motor de busca;

- Sites portais - são espaços que pretendem oferecer variados tipos de serviços. O seu objetivo é receber muitas visitas ao dia, com a finalidade de atrair um maior número de indivíduos para as informações e serviços disponibilizados. Geralmente os gestores destes sites ganham dinheiro através das diversas empresas de publicidade que comercializam os seus produtos através deste canal.

Os portais educacionais conseguem reunir uma série de atributos e características que os diferencia de outro site educativo qualquer.

Categorizar sites, tanto gerais como educativos, não constitui uma tarefa fácil, visto que todos os dias surgem novas categorias de sites. Recentemente, com a introdução da Web 2.0, novas categorias de sites surgiram, como por exemplo, os blogs e wikis, as redes sociais, etc.

\section{OS PORTAIS}

Desde os tempos mais remotos que o homem procura formas de publicar os seus conhecimentos e essa necessidade de mostrar, divulgar e disseminar a informação tornou-se uma necessidade cada vez mais latente nos dias atuais. "Durante muitos anos, o ato de publicar tem sido interpretado como o esforço requerido para suprir comunidades humanas de conteúdo" (AGNER, 2002, p.6).

A ideia de publicar e comunicar informação não é novidade, podendo ser observada desde a pré-história, quando os homens faziam desenhos nas cavernas (figuras rupestres) para indicar instruções de caça e sobrevivência a seus descendentes (SOUZA \& SOUZA, 2002). 
As formas de transmitir informação foram evoluindo passando por diversas fases, desde o papiro, os livros, as revistas e jornais, até chegarmos aos dias atuais, onde é possível publicar uma série de recursos através dos inúmeros ambientes disponíveis na Internet a que todos podem ter acesso com rapidez e facilidade.

A Internet constitui-se hoje num imenso repositório de conteúdos, em formato muito diversificado, que se encontram dispersos na rede em múltiplos ambientes, como: sites, repositórios, bases de dados online, enciclopédias e, também portais. Segundo Varejão, Santos \& Texeira (2008), nos últimos tempos, a Internet tem assistido um crescimento exponencial em múltiplas dimensões que variam desde o conjunto de tecnologias envolvidas até o volume de informação disponível.

A quantidade e a variabilidade das informações existentes na Internet faz com que muitos dados fiquem fora das buscas e pesquisas feitas pelos usuários, ou seja, os motores de busca, por mais robustos que sejam, não conseguem rastrear $100 \%$ das informações existentes na rede, visto que, em alguns ambientes, o acesso é restrito (como é o caso de algumas plataformas, bases de dados privadas, enciclopédias digitais registradas etc.). Além disso, outros documentos que se encontram em formato de imagem (como por exemplo, documentos digitalizados como imagens e disponibilizados online) podem também tornar o processo de recenseamento quase impossível. Neste sentido, os portais surgem como uma forma de suprir as necessidades de reunir grande quantidade de conteúdo num único ambiente, bem como facilitar a busca de documento por parte dos usuários.

Para lahn (2001), os portais constituem-se como meio de apresentação e recuperação da informação, permitindo a combinação de elementos como:

- Som - voz humana, música, efeitos especiais sonoros;

- Fotografia - imagens estáticas;

- Vídeo e animação - imagem em movimento;

- Desenhos em quadrinhos;

- Gráficos.

Um portal pode assumir diferentes significados dependendo da sua área de atuação. Porém, a única coisa que não se altera nas diferentes áreas é a sua filosofia, alicerçada em ser um local de entrada ou de fluxo de pessoas ou de informações.

O termo que hoje é utilizado como portal, em meados de 1994, era conhecido como mecanismo de busca, cuja finalidade era facilitar o acesso às informações disponíveis em vários documentos dispersos pela Web. Utilizando recursos de pesquisas e navegação associativa entre hiperligações, os mecanismos de busca auxiliavam os usuários a encontrar documentos na rede. Com o objetivo de minimizar o tempo para encontrar informações relevantes na Internet e ajudar os usuários menos experientes, alguns sites de busca começaram a utilizar o conceito de portal, agrupando sites e documentos em categorias predefinidas de acordo com o seu conteúdo. Em seguida, foram desenvolvidas ferramentas como: chat, comunidades de interesse e listas de discussão, personalização de conteúdo definido pelo usuário, acesso direto a conteúdos especializados entre outros (REYNOLDS \& KOULOPOULOS, 1999). Segundo Furtado (2004, p.48):

Não foi de forma aleatória que se recorreu à expressão portal no momento de adotar uma palavra para denominar os sítios de grande porte. O ponto de partida para a apropriação e ressignificação da palavra estava implícito nos próprios objetivos 
primordiais dos portais: fazer com que esses sítios sejam a porta de entrada, o lugar de início, o ponto de partida, o rito obrigatório de passagem para o ciberespaço.

Dias (2007), explica que o primeiro site a receber o nome de portal foi a AOL (América Online), que oferecia, na época, apenas acesso a Internet e um conjunto restrito de conteúdos. Mais adiante, os tradicionais sites de busca Yahoo e Excite deixaram de ser denominados de simples motores de busca, transformando-se em portais Web, passando a oferecer além de informações, serviços online, que fizeram com que houvesse um aumento do público para estes ambientes. lahn $(2002, \mathrm{~s} / \mathrm{p})$ afirma que "os portais evoluíram de sites que se limitam a catalogar a presença de outros sites na Internet, a verdadeiros centros com todo o tipo de informação, produtos e serviços".

Barbosa (2002) define os portais como "sites que centralizam informações gerais e especializadas, serviços de e-mail, canais de chat e relacionamento, shoppings virtuais, mecanismos de busca, entre outros".

Para Ma et al (2006, s/p) "a portal is a web presence that consolidates a variety of information and services e.g. searching, news, e-mail, discussion groups, and e-commerce." ${ }^{4}$ Para Reynolds, Shabajee \& Cayzer (2004, s/p) os "web-based information portals provide a point of access onto an integrated and structured body of information about some domain." 5 .

Segundo Ribeiro et al (2005, p.2607) "com a finalidade de se agrupar uma considerável quantidade de informações (através de conteúdo próprio ou links para outros sites) e de recursos de algum assunto, é que surgiram os Portais na Internet." Scheer (2002) afirma que um portal constitui um site na Internet, ou uma área dentro de um site, que atrai o público baseado no seu conteúdo.

Haguenauer, Cordeiro Filho e Mota (2008, s/p) acreditam que "os portais de Informação são aqueles capazes de organizar grandes acervos de conteúdo a partir dos temas ou assuntos neles contidos, conectando as pessoas às informações".Já Dias (2007, p.2) afirma que o "portal Web facilita o acesso às informações contidas em documentos espalhados pela Internet, oferecendo mecanismos de busca, hiperligações separadas por assunto, acesso a conteúdos especializados e comerciais, e personalização da sua interface".

Para Toledo (2002, p.12), "o portal é visto como um sistema de informação centrado no usuário, integrando e divulgando conhecimentos e experiências de indivíduos e equipes, atendendo, assim, às necessidades atuais (...) baseadas no conhecimento". Para Santos \& Andres (2007, s/p)

O portal propõe-se oferecer uma mistura de conteúdo e serviços, tais como correio eletrônico, mecanismos de busca, listas de discussão, por meio de uma interface compatível com seu público-alvo, e passível de ser personalizado pelo próprio usuário.

Desta forma, pode-se concluir que um portal é um endereço na Internet que funciona como um grande repositório e, ao mesmo tempo, um apontador para uma infinidade de outros sites ou subsites dentro do próprio portal ou a páginas exteriores. Na sua estrutura, podem identificar-se elementos como: um motor de busca, um conjunto considerável de áreas subordinadas com conteúdos próprios, uma área de notícias, um ou mais tópicos num fórum,

\footnotetext{
${ }^{4}$ Um portal é uma presença na Web, que consolida uma série de informações e serviços, por exemplo: pesquisa, notícias, e-mail, grupos de discussão, e e-commerce.

${ }^{5}$ Portais de informação baseados na Web provêm de um ponto de acesso a um corpo de informações integrado e estruturado sobre determinado domínio.
} 
outros serviços de geração de comunidades e um diretório, podendo incluir ainda outros tipos de conteúdos de acordo com a temática que aborda.

\begin{abstract}
La mayoría de los portales son gratuitos y constituyen una cortesía de sus patrocinadores (normalmente instituciones educativas y empresas del sector) hacia sus destinatarios. De esta manera, mediante la oferta de servicios de interés para los miembros de la comunidad educativa, pretenden difundir una buena imagen institucional o contactar con clientes potenciales. (MARQUES, 2001, s/p)
\end{abstract}

Grande (2003, p.19) classifica os portais em duas categorias: os horizontais e os verticais. Para o autor, "um portal horizontal pode ser entendido com um site com informações e serviços destinados a um público genérico, com o objetivo de atender às necessidades do maior número de pessoas possível, nos mais diversos assuntos". Já o portal vertical "é especializado em determinado seguimento específico, ou seja, procura "atender às necessidades de um determinado grupo de usuários relacionado a um único assunto ou a uma área de interesse" (GRANDE, 2003, p.19). Segundo Singh (2006, p.17), "they offer content and services aimed at a specific domain or community. Vortals can be focused on consumers with particular tasks, people at certain locations or communities with certain interests" ${ }^{7}$

Por outro lado, Cruz (2002) afirma que existem basicamente cinco tipos de portais, que podem ser utilizados de forma única ou mesmo combinados entre si. Entre os quais:

- O Portal Generalista (ou horizontal) - Tem como característica possuir um grande volume de dados, informações e conhecimento conectados de uma grande variedade de fontes. A sua finalidade é atender ao maior número possível de necessidades dos usuários;

- Portais Verticais (ou vortal) - São portais especializados em bens ou serviços específicos a uma temática;

- Portal de Conhecimento - Embora muito parecido com o portal generalista, esse tipo de portal diferencia-se por um detalhe importante: nele não existem dados e informações, mas somente conhecimento, ou seja, nele os dados e as informações já se encontram contextualizados;

- Portal de Negócio - É específico para transações comerciais;

- Portal Composto - Este portal pode conter todos os quatro tipos anteriores dentro de seus domínios.

Furtado (2004, p.51), afirma que por mais que os portais sejam diferenciados em categorias eles:

Têm em comum, além de um grande volume de informações, uma grande oferta de serviços aos internautas. Horizontais ou verticais, compartilham do objetivo de agrupar em suas páginas as principais ferramentas da Internet, de tal forma que os internautas possam explorar a potencialidade da rede, sem precisar recorrer a outros sítios.

Os portais (em sua grande maioria) são geralmente verticais, ou seja, possuem um assunto ou tema específico, visando a criação de uma comunidade virtual de interesses comuns,

\footnotetext{
${ }^{6}$ A maioria dos portais são gratuitos, e constituem uma cortesia de seus patrocinadores (normalmente instituições educativas e empresas do setor) aos seus destinatários. Desta maneira, mediante a oferta de serviços de interesse para os membros de uma comunidade educativa, pretendem difundir uma boa imagem institucional ou contactar potenciais clientes.

7 Eles oferecem conteúdo e serviços destinados a um domínio específico ou comunidade. Os Vortals podem ser focados nos consumidores com tarefas específicas, pessoas em determinados locais ou comunidades com certos interesses.
} 
com a possibilidade de agregação de um grande número de pessoas que compartilham os mesmos interesses.

A necessidade da criação de portais está diretamente relacionada com o acesso e troca de informação, obtenção de dados e aquisição de conhecimento sobre assuntos gerais e específicos. Para Ângulo e Albertin (2000, apud VIEIRA, PACHECO e RODRIGUES, 2004), as principais funções de um portal relacionam-se com a realização de buscas (informação ou conteúdos), com a comunicação e, também, com o comércio eletrônico.

Reynolds e Koulopoulos (1999) consideram um portal como sendo um sistema de informação centrado no usuário, integrando ou divulgando experiências de indivíduos e equipas, atendendo, assim, aos padrões atuais de instituições baseadas no conhecimento.

Para Eckerson (1999) os portais classificam-se em gerações e, atualmente encontram-se na terceira geração, conforme indicado na tabela 1.

Tabela 1: Gerações dos Portais

\begin{tabular}{|c|l|l|}
\hline Geração & Categoria & \multicolumn{1}{c|}{ Características } \\
\hline Primeira & Referencial & $\begin{array}{l}\text { Máquina de busca, com catálogo hierárquico de conteúdo } \\
\text { da Web. Cada entrada do catálogo contém descrição do } \\
\text { conteúdo com hiperligação. }\end{array}$ \\
\hline Segunda & Personalizado & $\begin{array}{l}\text { O usuário, através de um login e uma palavra passe, pode } \\
\text { criar uma visão personalizada do conteúdo do portal. Este } \\
\text { modo de visualização mostra apenas as categorias de maior } \\
\text { interesse para os usuários. O portal poderá ainda avisar o } \\
\text { usuário sempre que um novo conteúdo for adicionado às } \\
\text { categorias por ele escolhidas. }\end{array}$ \\
\hline Quarta & Especializado & $\begin{array}{l}\text { O portal incorpora aplicativos, tais como: correio } \\
\text { eletrônico, chat, listas de discussão, cotação da bolsa, } \\
\text { comércio eletrônico, leilões, permitindo ao usuário a } \\
\text { interação com o portal e com o seu conteúdo. Os usuários } \\
\text { podem selecionar essas aplicações para as suas páginas } \\
\text { pessoais. }\end{array}$ \\
\hline $\begin{array}{l}\text { Portais baseados em funções profissionais, para gestão de } \\
\text { atividades específicas na instituição, tais como: vendas, finanças, } \\
\text { recursos humanos, etc. }\end{array}$ \\
\hline
\end{tabular}

Conforme vimos nas categorias acima, os portais encontram-se muito vocacionados para a interação com o conteúdo. Neste sentido, a nível educacional, este tipo de ambiente poderá favorecer ao usuário, construtor do conhecimento, contribuir e partilhar aquilo que sabe/conhece com outros usuários do portal. No nível educacional, estes ambientes encontramse em ascensão, e, em língua portuguesa, já é possível encontrar um número considerável de exemplares na rede.

\section{OS PORTAIS EDUCACIONAIS}


Hoje podemos encontrar na Web uma enorme variedade de portais educacionais, uns mais gerais, outros mais específicos, embora muitos deles não reúnam os atributos que devem ser apanágio de um verdadeiro portal educacional. De fato, muitos constituem-se em simples repositórios de sites. Segundo Sampaio e Nascimento (2009, p. 1368):

Face à necessidade de os professores pesquisarem, desenvolverem e partilharem conteúdos e recursos educativos, aliada às vantagens das tecnologias para esse trabalho e desenvolvimento individual e coletivo, tem-se verificado uma procura e um desenvolvimento crescente de portais educacionais.

Um portal educacional deve ser capaz de proporcionar um ambiente colaborativo para o desenvolvimento, a avaliação e partilha de materiais e recursos educativos, o que levanta de imediato a questão da qualidade dos conteúdos disponibilizados e das funcionalidades técnicas do sistema (JAFARI \& SHEEHAN, 2003). Para Gonçalves (2002, p.137), os portais educacionais ${ }^{8}$ são:

Portas de acesso a outros websites de caráter educativo, para além de oferecerem ambientes Web que disponibilizam diversos serviços às comunidades educativas (professores, educadores, alunos e famílias): informação, mecanismos de pesquisa de dados, ferramentas de comunicação ou colaborativas, atividades didáticas e de formação, catálogos ou diretórios de recursos didáticos, materiais de apoio ou outros recursos educativos, entretenimento ou lazer, etc.

Para Furtado (2004), os portais educacionais são importantes, pois permitem a integração da Internet nos processos de educação formal, reunindo também experiências realizadas tanto na aprendizagem aberta, como a distância. Para lahn (2002), os portais educacionais não podem ser vistos apenas como ambientes virtuais, mas como ambientes de apoio e extensão das escolas no processo ensino e aprendizagem, classificando-os, ainda, como evoluções dos sites convencionais, pois são fontes de recursos e informações variados são interessantes para um público muito diversificado. lanh (2002, s/p) afirma que:

\footnotetext{
Os portais educacionais devem atender às necessidades dos seus visitantes, seja resolvendo dúvidas, propondo ideias e atividades inovadoras, como também dar total importância a qualidade do conteúdo que é disponibilizado e atualizado constantemente.
}

Na perspectiva de lanh (2001, 2002), Gonçalves (2002), Barroso (2005) e Bottentuit Junior \& Coutinho (2008), os portais educacionais têm como principal público-alvo:

- Os alunos, que entram no portal para pesquisar, estudar, conversar com outros usuários online e até para se divertir de forma construtiva e orientada;

- Os professores, que procuram um espaço para trocar experiências, fazer o acompanhamento extra sala de aula dos seus alunos, pesquisar sobre cursos e novidades na área de educação e, também, busca de materiais para utilização nas suas aulas;

- As escolas, que podem disponibilizar informações sobre as atividades desenvolvidas, os seus projetos educacionais e outras informações que julguem relevantes;

- Os visitantes, que encontram nestes ambientes um espaço para aprender, bem como para conhecer novas realidades e possibilidades a serem utilizadas nas suas atividades diárias;

\footnotetext{
${ }^{8}$ Portal geral de educação.
} 
- Investigadores e universidades, que vêem estes espaços como fontes de pesquisa e objetos de estudo para artigos, teses e dissertações;

- Editoras, que podem divulgar seus materiais, livros, revistas e manuais escolares;

- Outros portais, que poderão manter intercâmbio na divulgação mútua das suas informações e serviços.

No entanto, há muitos "falsos" portais educacionais disponíveis na Web. Alguns poderiam ser classificados como simples repositórios de outros sites, geralmente sem informações atualizadas, com poucos ou quase nenhuns serviços a oferecer aos usuários e, na maioria das vezes, sem nenhuma possibilidade de interação com os visitantes.

Para Marques (2001) \& Gonçalves (2002), um portal educativo, qualquer que seja a sua finalidade, deverá oferecer ao usuário, de forma estruturada, os seguintes atributos:

- Acesso a um vasto conjunto de conteúdos ou páginas Web, caracterizados pela diversidade dos elementos multimídia;

- Mecanismos que facilitem a pesquisa de conteúdos internos ou externos;

- Serviços genéricos, nomeadamente formas de comunicar, bem como de partilhar ideias e experiências (correio eletrônico, chat, fórum de discussão, transferência de arquivos e, em alguns casos, vídeo conferência, partilha de aplicações ou arquivos e publicação de conteúdos;

- Serviços específicos para professores, alunos e famílias, nos quais se incluem: recursos educativos diversos, conteúdos e atividades lúdico-didáticas de formação de legislação, filtragem de informação, ideias e sugestões escolares, entre outras informações de interesse educativo.

Como já foi referido, os portais educacionais, na sua maioria, enquadram-se na categoria de portais verticais, podendo ainda serem categorizados quanto à sua gestão, conforme refere Furtado (2004):

- Mantidos por organizações envolvidas na educação e que se valem da sua presença na rede para ampliar as suas atividades fins e fortalecer ações de marketing educativo;

- Os portais comerciais, montados por empresas que exploram o mercado de produtos educacionais para escolas da rede privada e pública e que visam apenas o lucro;

- E, por fim, os portais públicos criados por órgãos governamentais.

Os portais educacionais crescem em número e se fortalecem na Web de forma surpreendente. A cada instante, são fornecidas novas informações à comunidade educacional e são utilizados diferentes recursos tecnológicos para atrair, estimular e efetivamente auxiliar o estudante na sua longa jornada na aquisição de conhecimento. Assim como os sites convencionais, os portais, em qualquer que seja a classificação (educacional ou corporativo), podem ser passíveis de novas classificações e categorizações, dependendo da perspectiva com que são analisados.

\section{ESTUDOS COM PORTAIS EDUCACIONAIS}

Os portais tornaram-se objeto de estudo em diversas áreas do saber. Tanto no Brasil como em Portugal, é possível verificar desde publicações científicas até estudos a nível de mestrado e doutoramento abordando esta temática. Para ilustrar o que foi referido, apresentamos algumas investigações nesta área, disponíveis em língua portuguesa. 
Os estudos que serão mostrados possuem duas vertentes. A primeira centra-se no projeto e desenvolvimento de novos portais, necessitando, assim, da realização de estudos sobre a interface, a análise de requisitos e necessidades dos usuários. A segunda vertente situa-se na utilização dos portais que foram objeto de análise, com a finalidade de definir os requisitos de um bom portal educacional ou as vantagens a nível pedagógico que estes podem despertar nos usuários.

\section{ESTUDOS REALIZADOS NO BRASIL}

Nunes \& Santos (2006) procuram estabelecer uma relação entre portais educacionais e a teoria da aprendizagem significativa de David Ausubel, fornecendo uma base epistemológica para a análise pedagógica destes portais. Nesse sentido, os autores utilizam os mapas conceituais como ferramenta de análise, de forma a atender aos principais pressupostos da teoria da aprendizagem significativa. O objetivo da pesquisa foi contribuir com um método eficaz para avaliação de portais educacionais.

Batista \& Rocha (2006) apresentam o Portal Educacional do Colégio Sete de Setembro, que pretende ser mais um recurso pedagógico facilitador da aprendizagem dos alunos na Web. Segundo os autores, os alunos encontrarão nele todo o conteúdo programático da disciplina de Química, disponível no formato de aulas interativas, as quais serão constituídas de teorias, exercícios resolvidos e propostas de novos exercícios, bem como avaliação. As dúvidas que, porventura, possam surgir, poderão ser resolvidas pelo "Professor online" ou "Especialista", ou por recursos disponibilizados no portal educacional e que podem ser acessados pelos alunos mediante as suas necessidades.

lahn (2001), num estudo em nível de mestrado, realizou uma investigação com os Portais Educacionais existentes no Brasil, verificando o seu papel e contributo para a educação virtual. Segundo a autora, foi realizado um extenso recenseamento dos portais educacionais brasileiros, observando os serviços por eles fornecidos, seus procedimentos de trabalho e, por fim, qual a sua afinidade com a área (educação) e seus interesses específicos. Posteriormente, a autora fez um estudo comparativo destes portais, a fim de definir um modelo ideal para os estudantes, bem como indicar os requisitos necessários para que eles (portais) possam cativar, manter e auxiliar efetivamente o estudante na educação virtual.

Medeiros (2005), no seu estudo de caso da sua dissertação de mestrado, utilizou como instrumentos metodológicos as fichas de observações, os questionários e as entrevistas, com a finalidade de acompanhar a criação, a implantação e a utilização de um portal na Internet, caracterizado como um novo espaço de comunicação, de interação e de troca de informações entre a comunidade escolar. A investigação centrou-se na figura do educador e sua percepção acerca desse espaço. O resultado do estudo mostrou que portais educacionais podem ser utilizados por instituições de ensino de forma produtiva e colaborativa, entre todos os atores da comunidade educacional, desde que em tal processo seja levada em consideração, a cultura tecnológica da comunidade envolvida.

Soares (2006) apresenta um estudo de caso (dissertação de mestrado), realizado numa Escola na cidade de Campinas com a participação de alunos na faixa etária dos 10 aos 15 anos. Para esta investigação, utilizou o Design Participativo e a Semiótica Organizacional como referencial para tratar a melhoria de um portal infantil dedicado ao trabalho escolar de grupos. Este estudo, segundo a autora, envolveu atividades participativas com alunos, onde foi possível 
verificar a viabilidade da utilização da abordagem proposta. Um dos produtos deste trabalho foi a implementação do portal "CaleidoGrupos", que favoreceu a realização de um trabalho em grupo através de uma aplicação na Web.

\section{ESTUDOS REALIZADOS EM PORTUGAL}

Rocha (2003), no seu estudo, apresenta uma avaliação objetiva da qualidade e funcionalidades básicas dos portais Web das instituições portuguesas de ensino superior. Para avaliar os portais o autor utilizou uma ficha onde foi possível verificar uma série de atributos, tais como a taxa de presença na Internet, a qualidade e atualização dos conteúdos, as ferramentas de interação, a navegação, o tempo de carregamento, etc. As principais conclusões obtidas pelo autor indicam que a maioria dos portais que estavam presentes na Internet necessitava de melhorias para atingir o nível de qualidade desejável.

Gonçalves (2002), em sua dissertação de mestrado, desenvolveu um sistema de informação para a Web intitulado de "Portal dos Catraios - o portal dos miúdos e graúdos da Educação de Infância e do Ensino Básico". Como primeira tarefa, o autor analisou os modelos de desenvolvimento de sistemas de informação para a Web e, em seguida, selecionou o modelo mais adequado para o desenvolvimento do seu aplicativo. O portal concebido pelo autor permite, por um lado, a publicação de conteúdos lúdico-didáticos de aprendizagem, de divulgação e de dinamização de serviços por colaboradores, e, por outro lado, a consulta de conteúdos, a realização de atividades, a comunicação, participação e utilização de serviços por crianças, professores, pais e encarregados de educação.

Pinto (2006), no seu estudo de mestrado, teve como objetivo analisar as estratégias para o desenvolvimento da interface de portais didáticos, de modo a melhorar a qualidade do processo de ensino e aprendizagem. Nesse sentido, o autor apresenta o processo de concepção e desenvolvimento da interface de um portal orientado para uma vertente pedagógica. $O$ estudo resultou em dois projetos distintos: o portal da Universidade do Porto Júnior e o Projeto-piloto para exploração multidisciplinar de problemas de engenharia da Faculdade de Engenharia da Universidade do Porto (FEUP). Para consecução deste projeto, o primeiro passo, segundo o autor, foi à análise dos aspectos necessários para a concepção de interfaces na Web. Em seguida, procurou-se compreender os elementos envolvidos no design da interface, visando à criação de ambientes de interação que tentassem garantir a satisfação do usuário.

Barroso (2005), no seu estudo de mestrado, realizou uma investigação que teve como objetivo a concepção de um projeto de implementação de um portal para alojar as iniciativas do projeto-piloto para Exploração Multidisciplinar de Problemas de Engenharia - EMPE. Sendo um projeto interdepartamental e aberto, teve como propósito apoiar algumas ações multidisciplinares, estimular o aparecimento de outras e procurar envolver ainda outras instituições. O portal abrangeu três tipos de público: a comunidade em geral, os docentes e alunos do ensino secundário, investigadores e os alunos do ensino superior.

Gomes e Carvalho (2008) e Carvalho e Gomes (2009) apresentam dois estudos recentes sobre portais, o primeiro debruça-se sobre a apresentação da proposta de um portal temático sobre de avaliação de jogos e softwares educacionais e o segundo disponibiliza uma caracterização do portal, bem como os resultados de uma avaliação da usabilidade do ambiente desenvolvido pelos autores. 
Sampaio e Nascimento (2009) apresentam o portal intitulado "Professor Digital" que representa um ponto de acesso personalizado a professores que procuram ferramentas e recursos da Web 2.0 para utilização em contexto educativo. Além da caracterização deste ambiente, os autores apresentam também os resultados de um estudo da usabilidade do portal e a opinião dos avaliadores acerca dos vários pontos avaliados.

\section{CONSIDERAÇÕES FINAIS}

Conforme foi discutido neste artigo os portais constituem-se poderosos meios de acesso a informação e atualmente podemos observar a sua presença em várias áreas do conhecimento, no entanto, o alvo deste estudo se concentrou nos portais educacionais, que hoje em dia estão sendo utilizados para diferentes propósitos, tais como: ensino e aprendizagem dos alunos, para as pesquisas, para divulgação de informações científicas, etc. Estes portais tem sido alvo de pesquisas em vários níveis, tais como artigos científicos, dissertações de mestrado, teses de doutorado entre outros. Espera-se que este trabalho seja uma contribuição para que futuros investigadores possam conhecer os portais e diferencia-los de outros sites educativos disponíveis na web, bem como oferecer características essenciais para aquele que desejam conceber novos portais, bem como aprofundar-se neste domínio de conhecimento.

\section{REFERÊNCIAS BIBLIOGRÁFICAS}

1. AGNER, L. C. Otimização do diálogo usuários-organizações na World Wide Web: estudo de caso e avaliação ergonômica de usabilidade de interfaces humano-computador. Dissertação de Mestrado em Design. Rio de Janeiro: Pontifícia Universidade Católica do Rio de Janeiro, 2002.

2. ALVES, G. Internet: arcabouço midiático na era da financeirização. Revista Novos Rumos ano 15 , no 32, pp. 50-56, 2000.

3. ÂNGULO, M. J. \& AlBertin, A. L. Portais ou labirintos?. (Policopiado). 2000.

4. BARBOSA, S. Jornalismo digital e a informação de proximidade: o caso do portais regionais, um estudo sobre o UAl e o iBahia. Dissertação de Mestrado em Comunicação e Cultura Contemporânea. Salvador: Universidade Federal da Bahia. 2002.

5. BARROSO, A.C.R. Portal para a Divulgação de Projetos Multidisciplinares em Engenharia: Interface e Implementação. Mestrado em Tecnologia Multimídia. Faculdade de Engenharia. Porto Universidade do Porto, 2005.

6. BATISTA, F. E. F; ROCHA, M. N. Monitoria escolar on-line, uma nova Ferramenta de um portal educacional. Congresso Internacional de Educação a Distância. 2006. Disponível em: <http://www.abed.org.br/seminario2006/pdf/tc065.pdf> Acessado a 26/01/2009.

7. BOTTENTUIT JUNIOR, J. B.; COUTINHO, C. P. The Conception of a Rubric to Evaluate Educational Portals on the Web. In Proceedings of International Technology, Education and Development Conference, Valencia: International Association of Technology, Education and Development. Valencia. 2008. 
8. CARVALHO, A. A. A. Indicadores de Qualidades de Sites Educativos. Cadernos SACAUSEF Sistema de Avaliação, Certificação e Apoio à Utilização de Software para a educação e a Formação, Número 2, Ministério da Educação, 55-78. 2006.

9. CARVALHO, A. A. A.; GOMES, T. S. L. Portal de Avaliação Sobre Software Educativo Multimídia e Jogos. In P. DIAS, A. J. OSÓRIO (org.) Atas da VI Conferência Internacional de TIC na Educação. Braga: Universidade do Minho. pp.1967-1984. 2008

10.CARVALHO, A. A. A.; SIMÕES, A. \& SILVA, J. P. Indicadores de Qualidade e de Confiança de um Site. In M. P. Alves \& E. A. Machado (Ed.) Atas das II Jornadas da Secção Portuguesa da ADMEE: A avaliação e a validação das competências em contextos escolares e profissionais, Braga, Portugal: CIED, IEP. 2004

11.CASTELLS, M. A Galáxia da Internet: Reflexões sobre Internet, Negócios e Sociedade. Lisboa: Fundação Calouste Gulbenkian. 2004.

12.CASTELLS, M. A Sociedade em Rede. Lisboa: Fundação Calouste Gulbenkian. 2002

13.CRUZ, T. Gerência do Conhecimento. Enterprise Content Management. São Paulo: Cobra Editora e Marketing. 2002.

14.DIAS, C. Usabilidade na Web: criando portais mais acessíveis. 2a Ed. Rio de Janeiro: Editora Alta Books 2007.

15.ECKERSON, W. Plumtree blossoms: new version fullfills enterprise portal requirements. Boston, MA: Patricia Seybold Group, June 1999. Disponível em: <http://www.plumtree.com/moreinfo/specialoffer.htm. Acessado a 20/03/2009.>

16.EDWARDS, P. N. The Closed World. Cambridge, MA, MIT Press. 1996.

17.FURTADO, I. P. B. Portal ou Porteira? Os professores e uma experiência de integração da internet no ensino Fundamental por meio de um Portal Educativo. Dissertação de Mestrado em Educação Brasileira. Faculdade de Educação da Universidade Federal do Ceará. 2004.

18.GODFREY, A.G.M.W. Architecture and evolution of the modern web browser. 2006. Disponível em: <http://grosskurth.ca/papers/browser-archevol-20060619.pdf.> Acessado a 03/09/2008

19.GOMES, T. S. L.; CARVALHO, A. A. A. Portal@ avaliação de software educativo multimídia e ejogos. In J. Á. VELÁZQUEZ ITURBIDE; F. J. GARCÍA PEÑALVO; A. B. GIL GONZÁLEZ, (ed.) X Simpósio Internacional de Informática Educativa, Salamanca: Ediciones Universidad. 2008.

20.GONÇALVES, V.M.B. Desenvolvimento de Sistemas de Informação para Web: um portal para as escolas do 1 o ciclo e os jardins-de-infância. Dissertação de Mestrado em Tecnologia Multimídia. Faculdade de Engenharia. Porto: Universidade do Porto. 2002.

21.GRANDE, E. Perguntas mais frequentes. 2003. Disponível em: $<$ http://bredam.com.br/suporte/bibliot/pdfs/perguntas_frequentes.pdf.> Acessado em 29/04/2012

22. HAGUENAUER, C. J.; CORDEIRO FILHO, F.; MOTA, R. A. (2008). Desenvolvimento de Portais de Informação para Suporte a Comunidades Virtuais de Aprendizagem. In Revista Tecnologias na Educação, n1, Disponível em: <http://tecnologiasnaeducacao.pro.br/revista/a1n1/art5.pdf.> Acessado em 29/04/2012. 
23.IAHN, L. F. Portais Educacionais: uma realidade em evidência. Revista Aprender Virtual. Jul/Ago. 2002.

24.IAHN, L. F. Portal Educacional: uma análise do seu papel para a educação virtual. Dissertação de Mestrado em Engenharia de Produção, especialização em Mídia e Conhecimento. Universidade Federal de Santa Catarina. 2001.

25.JAFARI, A.; SHEEHAN, M. Designing portals Opportunities and Challenges. Hershey, PA: Information Science Publishing. 2003.

26.KALINKE, M. A. Internet na Educação, como, quando, onde, porquê. Curitiba: Editora Gráfica Expoente. 2003.

27.MA, C, BACON L.; PETRIDIS, M.; WINDALL G. Towards the Design of a Portal Framework for Web Services Integration. In Proceedings of the Advanced International Conference on Telecommunications and International Conference on Internet and Web Applications and Services. $2006 . \quad$ Disponível em: http://ieeexplore.ieee.org/stamp/stamp.jsp?arnumber=01602296. Acessado em 25/03/2009.

28.MARQUES, G. P. Nuevos instrumentos para la catalogación, evaluación y uso contextualizado de espacios web de interés educativo. Revista RITE, n0, pp.199-209. 2001.

29.MARQUES, M. A Escola no computador: linguagens rearticuladas, educação outra. ljuí, Editora UNIJUÍ. 1999.

30.MARTINS, C. F. G (2005). A Utilização da Internet pelo Consumidor Final do Turismo e as Perspectivas para o Futuro da Atividade. In M. Bahl, R.C.M. Rocha, S. F. Martins (Orgs.) O Turismo como Força Transformadora do Mundo Contemporâneo, pp. 335-347. São Paulo. Disponível em: <http://www.editoraroca.com.br/capas/conteudo441.pdf.> Acesso em 31/08/2008.

31.MEDEIROS, Z. A Apropriação da Cultura Tecnológica na Formação das Redes Sociotécnicas: um estudo sobre o portal da rede municipal de ensino de São Paulo. Dissertação de Mestrado em Educação Tecnológica. Belo Horizonte: Centro Federal Tecnológico de Minas Gerais. 2005.

32.NUNES, S. C.; SANTOS, R. P. Análise pedagógica de portais educacionais conforme a teoria da aprendizagem significativa. Revista Novas Tecnologias na Educação, CINTED-UFRGS, v. 4 № 1, Julho, 2006 p.13-21. Porto Alegre. Disponível em: <http://www.cinted.ufrgs.br/renote/jul2006/artigosrenote/a13_21149.> Acesso em 26/01/2009

33.PIAZZA, A. P. Uma abordagem para interoperabilidade Entre plataformas heterogêneas de serviços web para redes colaborativas de organizações. Dissertação de Mestrado em Engenharia Elétrica. Área de Concentração em Automação e Sistemas. Santa Catarina: Universidade Federal de Santa Catarina. 2007. 08/03/2009.

34.PINTO, J.M.C.C. Desenvolvimento da Interface de Portais Educacionais para Jovens. Dissertação de Mestrado em Tecnologia Multimídia. Faculdade de Engenharia. Porto: Universidade do Porto, 2006.

35.PÓVOA, M. Anatomia da Internet: investigações estratégicas sobre o universo digital. Rio de Janeiro: Casa da Palavra. 2000.

36.REINOLDS, H.; KOULOPOULOS, T. Enterprise information portals. New York: Merril Lynch, 16, Abril 2004. Disponível em: http://www.intelligenterprise.com/993003/feat1.shtml. Acesso em: 02/03/2012. 
37.REYNOLDS, D.,; SHABAJEE, P.; CAYZER, S. . Semantic Information Portals. ACM, New York, May 2004. Disponível em: <http://www.hpl.hp.com/techreports/2004/HPL-2004-67.pdf>. Acesso em 08/06/2012.

38.ROCHA, A. Qualidade dos Portais Web das Instituições Portuguesas do Ensino Superior: Avaliação Inicial. Atas da III Conferência Internacional sobre Tecnologias de Informação e Comunicação na Educação/5o SIIE (Simpósio Internacional em Informática Educativa), Braga. Portugal. 2003.

39.SAMPAIO, D.; NASCIMENTO, M. A. Implementação de um Portal para Professores Integrando Ferramentas Web 2.0. In P. DIAS, A. J. OSÓRIO (org.) Atas da VI Conferência Internacional de TIC na Educação Challenges 2009 / Desafios 2009. Braga: Universidade do Minho. pp.1367-1376. 2009.

40.SANTOS, A. S.; ANDRES, D. P. Usabilidade, Design Universal e Acessibilidade Para Portais Web. VIII Salão de Iniciação Científica e Trabalhos Acadêmicos: Guaiba: Universidade Luterana do Brasil. $2007 . \quad$ Disponível em: <http://guaiba.ulbra.tche.br/pesquisas/2007/artigos/sistemas/254.pdf.> Acessado a 04/03/2012. 41.SILVA, L. REMOALDO, P. Introdução a Internet. Lisboa: Editorial Presença. 1995.

42.SIMÕES, A. Avaliação de sites de Matemática e implicações na prática docente. Dissertação de Mestrado em Educação, especialidade em Tecnologia Educativa. Universidade do Minho. 2005.

43.SINGH, S. K. A. D. Development of a Networking Education Portal for Secondary Education Communities. Master Dissertation of Computer Science. Faculty of Computer Science and Information Technology. Kuala Lumpur: University of Malaya. 2006.

44.SOARES, S.C.M. Uma Abordagem Semiótica e Participativa para Customização de um Portal Infantil ao trabalho de Grupos. Dissertação de Mestrado em Ciência da Computação. Instituto de Computação. Campinas: Universidade Estadual de Campinas. 2006.

45.SOUZA, C. J.; SOUZA, A. A. A. Da Pré-História à Pós-Escrita. Revista Eletrônica de Ciêncais da Educação. Edição 1, vol. 01, no 01, Jun, 2002. Disponível em: <http://www.facecla.com.br/revistas/rece/trabalhos-num1/artigo01.pdf> .Acessado a 23/03/2012.

46.VAREJÃO, J.E.Q; SANTOS, S.; TEIXEIRA, R. PORTALSI - Portal de Tecnologia e Sistemas de Informação: especificação do front-end recorrendo a use-cases. In 50 Congresso Internacional de Gestão da Tecnologia e Sistema de Informação. São Paulo: Universidade de São Paulo. 2008.

47.VIEIRA, E. M. F.; PACHECO, R. C.; RODRIGUES, R. S. O Enfoque Cognitivo e o Uso das Tecnologias de Informação em Situação de Limitação Sensorial. Cadernos Ebape/FGV, Rio de Janeiro, v. 2, n. 2, 2004. 